\title{
Psychosocial and clinical factors associated with depression among individuals with diabetes in Bahir Dar City Administrative, Northwest Ethiopia
}

\author{
Teshager Woldegiorgis Abate ${ }^{*}$ and Haileyesus Gedamu
}

\begin{abstract}
Background: In a context of the potential epidemic nature of both diabetes mellitus (DM) and depression had negative effects in cases of disability and mortality. Coexisting depression had been linked to morbidity and mortality in people with diabetes. Therefore, this study aimed to identify psychosocial and clinical factors associated to develop depression symptoms in diabetes patients.

Methods: A systematic institution based cross-sectional study design was conducted from 1st March to 8th April 2016 among adult diabetes patent. Depression status was assessed by the Patient Health Questionnaire-9 (PHQ-9). Data were analyzed by logistic regression and at $\mathrm{P}<0.05$ with $95 \% \mathrm{Cl}$ was considered statistically significant.

Result: A total of 416 patients were included in this studied. Based on PHQ-9, self- reported depression symptom was 29.3\% [95\% Cl 25.2, 33.4]. In the performed statistical evaluation, patients whose age was between 45 and 54 years old $(A O R=3.88 ; 95 \% \mathrm{Cl} 1.36,11.08)$; being female ( $\mathrm{AOR}=2.43 ; 95 \% \mathrm{Cl} 1.29$, 4.58); who has poor social support $(\mathrm{AOR}=6.08 ; 95 \% \mathrm{Cl} 2.98,12.40)$; and who has high fear of kidney problems secondary to $\mathrm{DM}(\mathrm{AOR}=6.12 ; 95 \% \mathrm{Cl}$ $1.75,21.23)$ were statistically associated with depressive symptoms in diabetes patients.

Conclusion: This study demonstrated that complication fears, social support, being female and sexual dysfunction were found significantly associated with co-morbid depression in diabetes. Therefore, availed a social network of family and friends; providing diabetes education to address the patient's fear of complications; and considered a sexual function is an integral part of overall health in diabetic patients.
\end{abstract}

Keywords: Diabetes, Depression, Adult patient, Co-morbidity, Factors

\section{Background}

Diabetes mellitus (DM) is a chronic metabolic disorder. It affects the productive age group. Globally, an estimated 422 million. adults were living with diabetes in 2014. By 2030 this will have risen to 552 million. people. DM was a cause of 4.6 million. deaths in 2011 [1, 2]. Studies

*Correspondence: teshagerhylemarriam@gmail.com; woldegiorgist@yahoo. com

Department of Adult Health Nursing, College of Medicine and Health

Science, Bahir Dar University, Bahir Dar, Ethiopia showed that diabetes and depression occur together approximately twice as frequently as would be predicted by chance alone [3]. Depression is a common mental disorder characterized by sadness, loss of interest or pleasure, feelings of guilt or low self-worth, disturbed sleep or appetite, feelings of tiredness, and poor concentration [4]. Currently, at a global level, over 350 million. people are suffering from depression and its leading cause of disability [5].

It is believed that the relationship of diabetes to depression is bidirectional. That is why depression can lead to

c) The Author(s) 2020. This article is licensed under a Creative Commons Attribution 4.0 International License, which permits use, sharing, adaptation, distribution and reproduction in any medium or format, as long as you give appropriate credit to the original author(s) and the source, provide a link to the Creative Commons licence, and indicate if changes were made. The images or other third party material in this article are included in the article's Creative Commons licence, unless indicated otherwise in a credit line to the material. If material is not included in the article's Creative Commons licence and your intended use is not permitted by statutory regulation or exceeds the permitted use, you will need to obtain permission directly from the copyright holder. To view a copy of this licence, visit http://creativeco mmons.org/licenses/by/4.0/. The Creative Commons Public Domain Dedication waiver (http://creativecommons.org/publicdomain/ zero/1.0/) applies to the data made available in this article, unless otherwise stated in a credit line to the data. 
diabetes and conversely, diabetes could facilitate the emergence of depression [6]. Diabetes mellitus can cause psychological, emotional, social and psychosexual problems. Depression is also a risk factor as well as complications of diabetes $[5,6]$. Individuals with diabetes have a 2- to 3-fold increased risk for depression. Depression affecting approximately one in every five diabetes patients compared to the general population [5, 7]. Co-morbid diabetes and depression are a major clinical challenge as a treatment outcome of both conditions are worsened by one the other [3].

Previous studies documented that socio-demographic, clinical and psychosocial factors contributing to the development of co-morbid depression among diabetes patients. Socio-demographic factors that were significantly associated with depression in people with diabetes were; older age, lower socioeconomic status, monthly household income and ethnicity [8-10], level of education [12], female gender [13] and being single [14]. A clinical factors which were linked to depression in diabetic patients were presence of complication [12], co-morbidities, duration of treatment and treatment with insulin [10], duration of illness more than 10 years [15], limb problems [16], presence of $\geq 3$ diabetic complications, and negative life events and poor social support [17], total number of life events were statistically significant predictors of depression in diabetes patient [18].

Behavioral related factors that were significantly influenced co-morbid depression in diabetes patients were also: social inhibition and negatively affective life [19], poor social support $[14,20]$, physical quality of life [21], future diet behavior, physical activity and glucose testing [22]. A literature review reported that diabetes individuals who suffer from depression, DM related complications, and lack of social support were worse general health [23].

Psychosocial and clinical factors on co-morbid depression influence living with diabetes, both type 1 and type 2 [24]. Although the above factors were associated with depression, most of these studies were based on in developed countries, with only some exceptions. Therefore, these findings cannot be generalized to Ethiopia, especially in the study area. Thus, our study aimed to identify psychosocial and clinical factors associated with co-morbid depression among diabetes patients treated at the Felege Hiwot Referral Hospital (FHRH), Bahir Dar, Northwest Ethiopia.

\section{Methods}

\section{Study setting and population}

A facility-based cross-sectional study was conducted from 1st March to 8th April 2016 at FHRH. FHRH is found in Bahir Dar city administration, Northwest
Ethiopia. The hospital was opened for $24 \mathrm{~h}$ for emergency service. It provides promotive, preventive, curative and rehabilitative services.

The service was rendered by the physician and nurses. Around 1484 patients were registered for follow-up in the previous year. Those with diabetic patients were used to collect their medication on every 2 to 3-month basis. In the outpatient chronic follow up department, approximately 300 adult diabetes mellitus patients were seen weekly. All diabetic patients aged 18 years and older; and who had been on regular follow up treatment for DM regardless of ethnicity and religion were participating in the study. Hearing and/or verbalize impairment, serious illness and newly diagnosed during data collection were excluded from the study.

Participants were hearing and/or verbalizing impairment; those who did not provide coherent answers to the demographic questions. The participant was defined as a serious illness to difficult participate who had a severe medical or psychiatric illness that made it impossible to complete the study questionnaire in one setting, who were requested to terminate the interview for medical reasons, or the data collectors were perceived that the participant was too sick to participate. Participants were newly diagnosed means that they diagnosed before 6 months. This was by considering these participants could be perceived them an inadequacy awareness of the disease to get enough information.

\section{Sample size determination and sampling procedure}

The sample size was calculated by assuming a $5 \%$ marginal error (d), 95\% CI (alpha $=0.05)$ and 43.6 the proportion of depression among DM patients [25]. Based on this assumption, the sample size was calculated by the single population proportion formula: $\mathrm{n}=(\mathrm{Z} 1 \mathrm{t}-\alpha / 2) 2$ $\mathrm{p}(1-\mathrm{p}) / \mathrm{d} 2$; this yields an initial sample size of 378 . By considering a $10 \%$ non-response rate, 416 diabetic patients were planned and included in the study. A list of diabetic patients was obtained from the outpatient follow up department and used as a sampling frame.

The patients' records were listed in the follow-up appointment order. Then, the respondents were selected by using a systematic random sampling technique. Based on the decision to collect data for 1 month, the sampling interval was determined by dividing the expected number of diabetic patients per month (1320) into the sample size (416) which gives a sampling interval of three. Thus, every third patient coming to a follow-up service was interviewed until the total sample size was reached.

Data were collected using a face to face interview questionnaire to acquire demographic information; fear of diabetes complications [by using revised fear of complications questionnaire (FCQ)]; and social support (by 
using Oslo 3-items Social Support Questionnaire). To assess recent clinical related data: fasting plasma glucose level, co-morbidity, diabetes-related complications, duration of diabetes, treatment modality and duration of treatment were collected from the patients' records by using checklists. The sum of the Oslo 3-items social support scale was ranging from 3 to 14 . When social support scale scores were ranged from 3 to 8 is categorized as "poor support", 9-11 is "moderate support" and 12-14 is "strong support" [26, 27].

Fear of DM-rerated complication questionnaire was assessed specific fears (e.g. blindness, kidney problems, and heart disease, etc.), lifestyle fears, fears of hypoglycemia and future quality of life. It was a self-assessment questionnaire designed to measure fear of complications in diabetes. The items were rated on a four-point scale $(0-3)$, where 0 denotes a low fear of complications and 3 refers to high fear [28]. Perceived low fear of complication was recorded "no" fear of complication whereas perceived high fear of complication also recorded as "yes" had a fear of complication for each item.

Patients with established diabetes mellitus were evaluated for depression by interviewing nine-item of Patient Health Questionnaire nine (PHQ-9) adapted from Pfizer Inc. using local language (Amharic). PHQ-9 is a criteriabased diagnostics tool of depressive disorders and it was also a reliable and valid measure of depression severity. It is a brief questionnaire that scores each of 9 DSM-IV criteria for depression as "0" (not at all) to " 3 " (nearly every day). PHQ- 9 score $\geq 10$ had a sensitivity of $88 \%$ and specificity of $88 \%$ for major depression [29]. PHQ-9 scores of $5,10,15$, and 20 represent mild, moderate, moderately severe and severe depression, respectively [29,30].

Since the questionnaire was prepared in English, it was translated into the Amharic language for appropriate and easiness in interviewing the study subjects in the Amharic language. The psychometric properties and cross-cultural validation in the local language of PHQ-9 were validated in Ethiopia [31]. To assure data quality, two weeks before the actual data collection, the questionnaire was pre-tested on $5 \%$ of the sample among diabetes patients who were not included in the main study area. Data were collected by four trained, diploma nurses and two supervisors (BSc nurse). Additionally, on each data collection day, the collected data were reviewed and checked for its completeness by principal investigator and supervisors.

\section{Data analysis}

Data were entered and edited into EPI-data Version 3.1. The entered data was analyzed by using Statistical Package for Social Science (SPSS) for Windows program version 20 . The association was investigated to assess the association between dependent and explanatory variables using binary logistic regression. All explanatory variables with p-value $\leq 0.20$ in the bivariate logistic analysis were fitted into a multivariate logistic regression to identify independently associated factors in the final model. The degree of association was interpreted by using Odds Ratio with $95 \%$ confidence interval. The p-value $<0.05$ was considered statistically significant.

\section{Results}

\section{Socio-demographic characteristics}

Four hundred and sixteen study participants were interviewed with a response rate of $100 \%$. Of those, 290 (69.7\%) were married, and 120 (28.8\%) were governmental employees. Regarding age distributions, the mean and Standard Deviation (SD) age of the participants was $45.5 \pm 16.7$ years old. Likewise, the median family monthly income of the study participant was 2000 Ethiopian Birr (ETB) ( $\geq 1401)$ (Table 1).

Table 1 Socio-demographic characteristics of study participants at Felege Hiwot referral hospital, Bahir Dar, Northwest Ethiopia, $2016(n=416)$

\begin{tabular}{|c|c|c|c|}
\hline Variable & Category & Frequency & Percent \\
\hline \multirow[t]{2}{*}{ Sex } & Male & 242 & 58.2 \\
\hline & Female & 174 & 41.8 \\
\hline \multirow[t]{4}{*}{ Current age } & $18-34$ & 124 & 29.8 \\
\hline & $35-44$ & 81 & 19.5 \\
\hline & $45-54$ & 82 & 19.7 \\
\hline & $\geq 55$ & 129 & 31.0 \\
\hline \multirow[t]{2}{*}{ Residency } & Urban & 316 & 76.0 \\
\hline & Rural & 100 & 24.0 \\
\hline \multirow[t]{4}{*}{ Marital status } & Single & 65 & 15.6 \\
\hline & Married & 290 & 69.7 \\
\hline & Divorced & 32 & 7.7 \\
\hline & Widowed & 29 & 7.0 \\
\hline \multirow[t]{5}{*}{ Educational status } & Can't read and write & 124 & 29.8 \\
\hline & Read and write & 47 & 11.3 \\
\hline & Primary school (1-8) & 52 & 12.2 \\
\hline & $\begin{array}{l}\text { Secondary school } \\
(9-12)\end{array}$ & 84 & 20.2 \\
\hline & College/University & 109 & 26.2 \\
\hline \multirow[t]{5}{*}{ Occupational status } & House wife & 48 & 11.5 \\
\hline & Farmer & 103 & 24.8 \\
\hline & Merchant & 65 & 15.6 \\
\hline & $\begin{array}{l}\text { Governmental } \\
\text { employee }\end{array}$ & 135 & 32.5 \\
\hline & $\begin{array}{l}\text { Private company } \\
\text { employee }\end{array}$ & 65 & 15.6 \\
\hline \multirow{3}{*}{$\begin{array}{l}\text { Average monthly } \\
\text { income }\end{array}$} & $\leq 650$ & 111 & 26.7 \\
\hline & $651-1400$ & 101 & 24.3 \\
\hline & $\geq 1401$ & 204 & 49.0 \\
\hline
\end{tabular}




\section{Clinical characteristics of study participant}

About 238 (57.2\%) patients were found to have type-II DM. Patients with type-I DM were taken the injectable form of treatment (insulin). Out of 416 participants, $70(16.8 \%)$ participants had a cardiovascular disease (like hypertension) which was evidenced by a review of patients' cards. Three hundred nineteen (76.7\%) and $321(77.2 \%)$ were living with diabetes mellitus and taking physician-prescribed medication at least for 8 years respectively (Table 2 ).

\section{Psychosocial factors attribute to depression in the study participants}

Of the total study participant, 213 (51.2\%) were reported that they had poor social support. Regarding perceived fear of complication, 222 (53.4\%) of respondents had fear of long-term diabetes complication, 109 (26.2\%) participants were reported worrying about future problems when their blood sugars were erratic and 171 (41.1\%) were worried about losing their eyesight because of diabetes related-complication (Table 3).

\section{Factors associated with depression}

The multivariate logistic regression analysis showed that participants with age $45-54(\mathrm{AOR}=3.88 ; 95 \% \mathrm{CI} 1.36$, 11.08), being female ( $\mathrm{AOR}=2.43$; ( $95 \% \mathrm{CI} 1.29,4.58)$; who had sexual dysfunction $(\mathrm{AOR}=9.52 ; 95 \%$ CI 2.19, 41.35); those who had moderately support in social life $(\mathrm{AOR}=6.49 ; 95 \% \mathrm{CI} 2.83,14.87)$; who had socially poor supported $(\mathrm{AOR}=6.08 ; 95 \% \mathrm{CI} 2.98,12.40)$; those who were worried about heart disease due to diabetes $(\mathrm{AOR}=6.49 ; 95 \% \mathrm{CI} 2.22,18.93)$ and who had a high fear of kidney problem in their future life $(A O R=6.12$; $95 \%$ CI $1.75,21.23$ ) were more likely had co-morbid depression disorder (Table 4).

Patients who were 45-54 years had a significantly higher risk of having depression symptoms than those ages less than 45 and greater than 55 years $(\mathrm{AOR}=3.88$; $95 \%$ CI 1.36, 11.08). Females were 2.43 times more likely to develop depressive symptoms as compared to males $(\mathrm{AOR}=2.43$; $(95 \%$ CI 1.29, 4.58). Participants who were suffering from sexual dysfunction 9.52 times more likely attack by depression symptoms as compared to those who had no sexual problems (AOR $=9.52 ; 95 \%$ CI 2. 19, 41.35). There were also significant difference regarding

Table 2 Clinical characteristics of study participants at Felege Hiwot referral hospital, Bahir Dar, Northwest Ethiopia, $2006(n=416)$

\begin{tabular}{|c|c|c|c|}
\hline Variable & Category & Frequency & Percent \\
\hline \multirow[t]{2}{*}{ Types of diabetes mellitus } & Type 1 & 178 & 42.8 \\
\hline & Type 2 & 238 & 57.2 \\
\hline \multirow[t]{3}{*}{ Diabetes treatment regime } & Oral hypoglycemic and insulin & 60 & 14.4 \\
\hline & Oral hypoglycemic agent only & 124 & 29.7 \\
\hline & Single insulin only & 232 & 55.8 \\
\hline \multirow[t]{3}{*}{ Duration of DM (years) } & $\leq 8$ & 319 & 76.7 \\
\hline & $9-16$ & 80 & 19.2 \\
\hline & $\geq 17$ & 17 & 4.1 \\
\hline \multirow[t]{3}{*}{ Duration of DM Rx (years) } & $\leq 8$ & 321 & 77.2 \\
\hline & $9-16$ & 75 & 18.0 \\
\hline & $\geq 17$ & 20 & 4.8 \\
\hline \multirow[t]{5}{*}{ Comorbid disease } & Cardiovascular disease & 70 & 16.8 \\
\hline & Respiratory disease & 9 & 2.2 \\
\hline & Neurological disease & 12 & 2.9 \\
\hline & Renal disease & 11 & 2.6 \\
\hline & Others disease & 13 & 3.1 \\
\hline \multirow[t]{4}{*}{ Complication of diabetes } & Diabetic retinopathy & 53 & 12.7 \\
\hline & Diabetic nephropathy & 8 & 1.9 \\
\hline & Diabetic neuropathy & 14 & 3.4 \\
\hline & Sexual dysfunction & 19 & 4.6 \\
\hline \multirow{3}{*}{$\begin{array}{l}\text { Three consecutive average measurement of fasting } \\
\text { plasma glucose level }\end{array}$} & $>126 \mathrm{mg} / \mathrm{dl}$ & 262 & 63.0 \\
\hline & $<72 \mathrm{mg} / \mathrm{dl}$ & 13 & 3.1 \\
\hline & $72 \mathrm{mg} / \mathrm{dl}-126 \mathrm{mg} / \mathrm{dl}$ & 141 & 33.9 \\
\hline
\end{tabular}


Table 3 Psychosocial characteristics of study participants at FHRH, Bahir Dar, Northwest Ethiopia, 2016 (n=416)

\begin{tabular}{|c|c|c|c|}
\hline Variables & Categories & Frequency & Percent \\
\hline \multirow[t]{3}{*}{ Social support ${ }^{a}$} & Strong support & 71 & 17.1 \\
\hline & Moderate support & 132 & 31.7 \\
\hline & Poor support & 213 & 51.2 \\
\hline \multirow[t]{2}{*}{ Burden of medication } & $\leq 3$ & 346 & 83.2 \\
\hline & $\geq 4$ & 70 & 16.8 \\
\hline \multirow[t]{2}{*}{ I feel afraid of long-term complications of diabetes ${ }^{a}$} & High fear & 222 & 53.4 \\
\hline & Low fear & 194 & 46.6 \\
\hline \multirow[t]{2}{*}{ I am scared that diabetes could affect my feet } & High fear & 193 & 46.4 \\
\hline & Low fear & 223 & 53.6 \\
\hline \multirow[t]{2}{*}{ I am afraid I may need kidney dialysis one day } & High fear & 139 & 33.4 \\
\hline & Low fear & 277 & 66.6 \\
\hline \multirow[t]{2}{*}{ I worry about losing my eyesight because of diabetes } & High fear & 171 & 41.1 \\
\hline & Low fear & 245 & 58.9 \\
\hline \multirow[t]{2}{*}{ I worry diabetes increases chances of heart disease } & High fear & 122 & 29.3 \\
\hline & Low fear & 294 & 70.7 \\
\hline \multirow{2}{*}{$\begin{array}{l}\text { Afraid of developing long-term complications as a result of frequent } \\
\text { high blood sugars }\end{array}$} & High fear & 128 & 30.8 \\
\hline & Low fear & 288 & 69.2 \\
\hline \multirow[t]{2}{*}{ I am afraid I will develop kidney problems one day } & High fear & 110 & 26.4 \\
\hline & Low fear & 306 & 73.6 \\
\hline \multirow[t]{2}{*}{ I worry that I might be at higher risk for having a stroke } & High fear & 94 & 22.6 \\
\hline & Low fear & 322 & 77.4 \\
\hline \multirow[t]{2}{*}{ Worry about your future health? } & High fear & 108 & 26.0 \\
\hline & Low fear & 308 & 74.0 \\
\hline \multirow[t]{2}{*}{ Worry about future when your blood sugars are erratic } & High fear & 109 & 26.2 \\
\hline & Low fear & 307 & 73.8 \\
\hline
\end{tabular}

a Social support was assessed by using Oslo 3-items Social Support Questionnaire and fear of complication was measured by revised fear of complications questionnaire (FCQ)

social support; moderate, socially supported were 6.49 times more likely to develop depressive symptoms as compared to those strongly supported $(\mathrm{AOR}=6$. 49; $95 \%$ CI 2.83, 14.87). Patients who had a high fear for kidney problems related to diabetes were 6.12 times more likely to develop depressive symptoms as compared to those who had low fear (AOR $=6.12$; 95\% CI 1.75, 21.23) (Table 4).

\section{Discussion}

To our knowledge, there is high impact of depression and co-morbid diabetes and its importance as a public health problem, little is known about the existence of depression in people with diabetes in the Amhara region, especially in Bahir Dar city. Therefore, this study aimed to assess psychosocial and clinical factors associated with depression among diabetes patients attending FHRH, Bahir Dar Northwest Ethiopia. In this study, age was the significantly associated depression symptom in diabetes patients. The risk factors for depression as per the bivariate analysis in this study were age, being female, presence of sexual dysfunction, moderate and poor social support, high fear of developing cardiac and kidney diseases for their future life.

In this study, age (45-54 years old) 3.88 times has a risk of developing depressive symptoms than those whose age was greater than 54 and less than 45 years old. This finding was alongside with other previous works done in different countries [9-11]. In this study, depression was significantly associated with the female gender that was 2.43 times has a risk to develop an attack of depressive symptoms than males. This finding confirms other studies done in Karnataka, Southern India and Peshawar [10, $32,33]$.

The results of this study indicated that moderate and poor social support were significantly associated with depression symptoms. Participants who had a lack of social support from their families, neighbors, and friends were around 6.4 times more vulnerable to develop depression symptoms than participants who had strong social support. This finding was in agreement with studies conducted in Iran $[14,20]$, Croatia 
Table 4 Logistic regression on the impact of selected socio-demographic, clinical and psychosocial factors, and depression symptoms among diabetes at FHRH, Bahir Dar, Northwest Ethiopia, $2016(n=416)$

\begin{tabular}{|c|c|c|c|c|}
\hline \multirow{2}{*}{$\begin{array}{l}\text { Variable categories } \\
\text { Age }\end{array}$} & \multicolumn{2}{|c|}{ Depression (n) } & \multirow[t]{2}{*}{ COR $(95 \% \mathrm{Cl})$} & \multirow[t]{2}{*}{ AOR $(95 \% \mathrm{Cl})$} \\
\hline & Yes & No & & \\
\hline $18-34$ & 37 & 87 & $1.53(0.87,2.71)$ & $1.83(0.69,4.88)$ \\
\hline $35-44$ & 24 & 57 & $1.52(0.81,2.86)$ & $4.22(1.65,10.76)$ \\
\hline $45-54$ & 33 & 49 & $2.43(1.32,4.46)$ & $3.88(1.36,11.08)$ \\
\hline$\geq 55^{*}$ & 28 & 101 & 1.00 & 1.00 \\
\hline \multicolumn{5}{|l|}{ Sex } \\
\hline Male* & 61 & 181 & 1.00 & 1.00 \\
\hline Female & 61 & 113 & $1.60(1.05,2.45)$ & $2.43(1.29,4.58)$ \\
\hline \multicolumn{5}{|l|}{ Sexual dysfunction } \\
\hline Yes & 11 & 8 & $3.54(1.39,9.04)$ & $9.52(2.19,41.35)$ \\
\hline $\mathrm{No}^{*}$ & 111 & 286 & 1.00 & 1.00 \\
\hline \multicolumn{5}{|l|}{ Social support } \\
\hline Strong support* & 25 & 188 & 1.00 & 1.00 \\
\hline Moderate support & 55 & 77 & $10.89(5.78,20.47)$ & $6.49(2.83,14.87)$ \\
\hline Poor support & 42 & 29 & $5.37(3.12,9.24)$ & $6.08(2.98,12.40)$ \\
\hline \multicolumn{5}{|c|}{$\begin{array}{l}\text { I worry that having diabetes increases } \\
\text { the chances of heart disease }\end{array}$} \\
\hline High fear & 74 & 48 & $7.90(4.90,12.73)$ & $6.49(2.22,18.93)$ \\
\hline Low fear* & 48 & 246 & 1.00 & 1.00 \\
\hline \multicolumn{5}{|c|}{$\begin{array}{l}\text { Afraid to develop kidney problems } \\
\text { one day }\end{array}$} \\
\hline High fear & 69 & 41 & $8.03(4.94,13.07)$ & $6.12(1.75,21.23)$ \\
\hline Low fear* & 53 & 253 & 1.00 & 1.00 \\
\hline
\end{tabular}

* Reference category; p-value = significant, $<0.05 ;$ COR Crude Odds Ratio, AOR Adjusted Odds Ratio

[21], Korea [34] and Addis Ababa [17]. This might be due to the effect of social support on emotional wellbeing (as in receiving love and empathy) and practical help (like the gifts of money, assistance with care). Hence, social support can come from social connectedness, feeling needed, a reassurance of self-worth, reliable support, advice and information, and physical and material assistance.

In our study, depression symptoms 9.52 times increased with the presence of sexual dysfunction in diabetes patients. This finding was supported by other previous studies that reported the presence of complications was strongly associated with depression symptoms in diabetes patients [10], the burden of a lifelong disorder of sexual problems [6]. The nature of diabetes mellitus is producing hyperglycemia, as well as angiopathy, vasculopathy, and neuropathic complication leads to sexual dysfunction in both genders [35]. This might be due to the pathophysiological effect of DM on sexual function through changes in blood supply to the urogenital tissue, reduce to genital lubrication, inability to achieve orgasm, dyspareunia and reduction in libido [36].

But other diabetes clinical risk factors that were significantly associated in varying degree with depression in people with diabetes includes hypertension and microvascular complication [37], diabetic nephropathy [17], physical activities, glucose testing [22], presence of comorbidities, longer duration of treatment, treatment with insulin [10] and elevated fasting blood sugar level, physical disability and lack of a physician's advice about lifestyle modifications [32]. Those variables in our study did not significant risk factors to provoke the attack of depressive symptoms in DM patients. This discrepancy might be due to variations in study design and setting, self-care characteristics of respondents, a therapeutic relationship of care provider, sedentary lifestyle of the participants and selection method of respondents.

In this study, high fear of future complication was found to be independently associated with developing depression in diabetes participants. Perceived high fear of cardiac complication with the adjusted odds ratio of 6.49 $(2.22,18.93)$, and perceived high fear of kidney complications with the adjusted odds ratio of $6.12(1.75,21.23)$ was strongly associated with developing depression. However, other studies were done in Karnataka [10], Iran [9], India [32] and Addis Ababa [17] which found no significant association in terms of fear of complications in diabetes patients. This discrepancy was might be due to 
almost all other studies that did not investigate the fear of complications. Another possible reason might be earlier studies focused on only demographic, clinical and psychosocial factors related to co-morbid depression in diabetes.

\section{Conclusion}

In the current study, clinical factors (sexual dysfunction, sex, and age) and psychosocial factors (social support, fear of complication) were important factors significantly associated with co-morbid depression with patients living diabetes, both type 1 and type 2 . To be promoted to optimal medical outcomes and psychological well-being, patient-centered care is essential. Therefore, the health care providers should be availed of a social network of family and friends (because family and friends are a significant source of support for coping mechanisms); providing diabetes education to address patient's fear of long-term complications by fear reduction and promote survive skill. Sexual function also should be considered an integral part of overall health in diabetic patients.

\section{Strength}

The study could be considered as a base for further similar and large-scale studies. The strengths of this study also a significant contribution to the body of knowledge in general and more specifically for health professionals and the patients themselves. Additionally, rather than having to rely on self-report, we were able to use information from patients' medical diaries to gather information about the presence of diabetes complications, co-morbidity, and FBS levels. Also, we were using a reasonable sample size.

\section{Limitation}

Due to the cross-sectional design of this study, it is not possible to draw any conclusion regarding causality. We also assessed level depression and other independent variables by using self-reported question turns to limit this study. Carefully analyzing longitudinal data and mixed design both qualitative and quantitative approaches are the best alternative in the future.

\footnotetext{
Abbreviations

AOR: Adjusted odd ratio; Cl: Confident interval; DM: Diabetes mellitus; DSM-IV: Diagnostic and Statistical of Mental Disorder-5; FCQ: Fear of Complication Questionnaires; FHRH: Felege Hiwot Referral Hospital; PHQ-9: Patent Health Questionnaires Nine.
}

\section{Acknowledgements}

We are heart full thank goes to Addis Ababa University for all expenses of the research work, and data collectors and all the study participants who voluntarily participated in this study.

\section{Authors' contributions}

TWA initiated the idea, carried out the study, and was involved in drafting and editing the manuscript, and interpretation of the data. HG contributed to editing the proposal; critically revised the paper, and provided the final version. All authors read and approved the final manuscript.

\section{Funding}

The study was funded by the Addis Ababa University. The University was critically reviewed and approved the proposal of the study, permitted the study to be conducted, and was involved in data collection process manuscript preparation.

\section{Availability of data and materials}

Detailed data will not be shared due to the confidential nature of the data.

\section{Ethics approval and consent to participate}

This study was approved by Addis Ababa University College of health science Ethical Institutional Review Board committee and ethical approval and clearance were obtained from this committee. Permission and supportive letters were obtained from the respective health bureau and the hospital medical director's office before actual data collection. Participation was voluntary and information also was collected anonymously after obtaining written consent from each respondent by assuring confidentiality throughout the data collection period. Participants also were told the objective of the study and gave the right to refuse, stop or withdraw at any time of data collection. Patients found to have severe depression were referred to psychiatry clinic for further assessment and treatment.

\section{Consent for publication}

Not applicable.

\section{Competing interests}

The authors declare that they have no competing interests.

Received: 5 December 2018 Accepted: 22 February 2020

Published online: 11 March 2020

\section{References}

1. Atlas D. International diabetes federation IDF Diabetes Atlas. 7th ed. Brussels: International Diabetes Federation; 2015.

2. WHO. W. Global report on diabetes. Geneva: World Health Organization; 2016

3. Holt RI, de Groot M, Golden SH. Diabetes and depression. Curr Diabetes Rep. 2014;14(6):491.

4. World Health Organization. Depression: a global crisis. World Mental Health Day. Occoquan: World Federation for Mental Health; 2012.

5. Marcus M, Yasamy MT, van Ommeren MV, Chisholm D, Saxena S. Depression: A global public health concern. 2012.

6. Moulton CD, Pickup JC, Ismail K. The link between depression and diabetes: the search for shared mechanisms. Lancet Diabetes Endocrinol. 2015;3(6):461-71.

7. Shoib S, Mushtaq R, Tasleem A, Hayat BM. Depression and diabetes: common link and challenges of developing epidemic !! J Psychiatry. 2015;18(2):14-164.

8. Menezes J, de Morais H, Dias I, Schreiber A, Souza C, da Cunha J. Depression associated with diabetes: from pathophysiology to treatment. Curr Diabetes Rev. 2016;12(3):165-78.

9. Yekta Z, Pourali R, Yavarian R. Behavioural and clinical factors associated with depression among individuals with diabetes. Eastern Mediterr Health J. 2010;16(3):286-91.

10. Taranum A, Angadi N, Shakeel M. A study of frequency and factors associated with depression among adult diabetics in urban areas of Davangere. Karnataka Diabetic Foot. 2016;24:26-7.

11. Ganasegeran K, Renganathan P, Manaf RA, Al-Dubai SA. Factors associated with anxiety and depression among type 2 diabetes outpatients in Malaysia : a descriptive cross-sectional single-center study. BMJ BMJ Open. 2014;4(4):e004794 
12. Mohamed R, Abdul Kadir A, Yaacob LH. A study on depression among patients with type 2 diabetes mellitus in North-Eastcoast Malaysia. Int J Coll Res Inter Med Public Health. 2012;4(8):1589-600.

13. Agbir MT, Adebowale TO, Audu MD, Goar SG, Puepet FH, Osika MW. Clinical correlates of depression among diabetics in Jos, Nigeria. J Med Trop. 2010;12:1.

14. Behshid G, Reza BM, Samaneh M. Psychosocial contributing factors that affect mental well being in diabetic patients. Russian Open Med J. 2013;2:1.

15. Verma SK, Luo N, Subramaniam M, Sum CF, Stahl D, Liow Chong SA. Impact of depression on health-related quality of life in patients with diabetes. Ann Acad Med Singapore. 2010;39(12):913-7.

16. Bahari R. The psychological impact of diabetic limb problems. Int Med J Malaysia. 2015;14(2):3-7.

17. Habtewold TD, Alemu SM, Haile YG. Sociodemographic, clinical, and psychosocial factors associated with depression among type 2 diabetic outpatients in Black Lion General Specialized Hospital, Addis Ababa, Ethiopia: a cross-sectional study. BMC Psychiatry. 2016;16(1):103.

18. Ferreira MC, Piaia C. Clinical variables associated with depression in patients with type 2 diabetes. Revista Brasileira. 2015;61(4):336-40.

19. van Dooren FE, Denollet J, Verhey FR, Stehouwer CD, Sep SJ, Henry RM, Kremers SP, Dagnelie PC, Schaper NC, van der Kallen CJ, Koster A. Psychological and personality factors in type 2 diabetes mellitus, presenting the rationale and exploratory results from The Maastricht Study, a population-based cohort study. BMC Psychiatry. 2016;16(1):17.

20. Yazdi RS, Taslimi Z, Ahmadpanah M, Ghaleiha A. Adjustment to diabetes among diabetic patients: the roles of social support and self-efficacy. Avicenna J Neuro Psych Physio. 2016;3(1): e37470. https://doi.org/10.17795/ ajnpp-37470.

21. Pibernik-Okanovic M, Begic D, Peros K, Szabo S, Metelko Z. Psychosocial factors contributing to persistent depressive symptoms in type 2 diabetic patients: a Croatian survey from the European Depression in Diabetes Research Consortium. J Diabetes Compl. 2008;22(4):246-53.

22. Aikens JE. Prospective associations between emotional distress and poor outcomes in type 2 diabetes. Diabetes Care. 2012;35(12):2472-8.

23. Lewko J, Misiak B. Relationships between Quality of Life, Anxiety, Depression, and Diabetes. Ann Depr Anxiety. 2015;2(1):1-2.

24. Young-Hyman D, De Groot M, Hill-Briggs F, Gonzalez JS, Hood K, Peyrot M. Psychosocial care for people with diabetes: a position statement of the american diabetes association: a position statement of the American Diabetes Association. Diabetes Care. 2016;39(12):2126-40.

25. Dejene S, Negash A, Tesfay K, Jobset A, Abera M. Depression, and Diabetes in Jimma University Specialized Hospital, Southwest Ethiopia. J Psychiatry. 2014;17(126):2.
26. Abiola T, Udofia O, Zakari M. Psychometric properties of the 3-item oslo social support scale among clinical students of Bayero University Kano. Nigeria Malaysian J Psychiatry. 2013;22(2):32-41.

27. Dalgard OS, Dowrick C, Lehtinen V, Vazquez-Barquero JL, Casey P, Wilkinson G, Ayuso-Mateos JL, Page H, Dunn G. Negative life events, social support and gender difference in depression. Soc Psychiatry Psychiatr Epidemiol. 2006:41(6):444-51.

28. Taylor EP, Crawford JR, Gold AE. Design and development of a scale measuring fear of complications in type 1 diabetes. Diabetes/Metabolism Res Rev. 2005;21(3):264-70.

29. Kroenke K, Spitzer RL, Williams JB. The PHQ-9: Validity of a brief depression severity measure. J Gen Intern Med. 2001;16(9):606-13.

30. Kroenke K, Spitzer RL. The PHQ-9: a new depression diagnostic and severity measure. Psychiatr Ann. 2002;32(9):509-15.

31. Bizuayehu G. Diagnostic Validity of Patient Health Questionnaire-9 and Composite International Diagnostic Interview Assessment Scales for Depression in East Africa (Doctoral dissertation). 2013.

32. Mathew M, Abish A, Kuriakose A, Isaiah JR, Kiran AM, Vijayakumar K. Predictors of depression among patients with diabetes mellitus in Southern India. Asian J Psychiatry. 2013;6(4):313-7.

33. Khan MA, Sultan SM, Nazli R, Akhtar T, Khan MA, Sher N, Aslam H. Depression among patients with type-II diabetes mellitus. J Coll Phys Surg Pak. 2014;24(10):770-1.

34. Lee BJ, Lamichhane DK, Jung DY, Moon SH, Kim SJ, Kim HC. Psychosocial factors and psychological well-being: a study from a nationally representative sample of Korean workers. Industrial Health. 2016;54(3):237-45.

35. Gandhi J, Dagur G, Warren K. Effect of diabetes mellitus on sexual arousal and intercourse. Transl Biomed. 2016;7:2.

36. Meeking DR, Fosbury JA, Cummings MH. Sexual dysfunction and sexual health concerns in women with diabetes. Pract Diabetes. 2013;30(8):327-31.

37. Thour A, Das S, Sehrawat T, Gupta Y. Depression among patients with diabetes mellitus in North India evaluated using patient health questionnaire-9. Indian J Endocrinol Metab. 2015;19(2):252.

\section{Publisher's Note}

Springer Nature remains neutral with regard to jurisdictional claims in published maps and institutional affiliations.
Ready to submit your research? Choose BMC and benefit from:

- fast, convenient online submission

- thorough peer review by experienced researchers in your field

- rapid publication on acceptance

- support for research data, including large and complex data types

- gold Open Access which fosters wider collaboration and increased citations

- maximum visibility for your research: over 100M website views per year

At BMC, research is always in progress.

Learn more biomedcentral.com/submissions 